\title{
Bas Ter Haar Romeny (ed.). Religious Origins of Nations? The Christian Communities of the Middle East
}

Florence Jullien

\section{(2) OpenEdition \\ 1 Journals}

\section{Édition électronique}

URL : http://journals.openedition.org/abstractairanica/40891

DOI : 10.4000/abstractairanica.40891

ISSN : 1961-960X

Éditeur :

CNRS (UMR 7528 Mondes iraniens et indiens), Éditions de l'IFRI

\section{Édition imprimée}

Date de publication : 1 décembre 2013

ISSN : 0240-8910

Référence électronique

Florence Jullien, «Bas Ter Haar Romeny (ed.). Religious Origins of Nations? The Christian

Communities of the Middle East », Abstracta Iranica [En ligne], Volume 32-33 | 2013, document 349, mis en ligne le 01 juillet 2016, consulté le 26 septembre 2020. URL : http://journals.openedition.org/ abstractairanica/40891 ; DOI : https://doi.org/10.4000/abstractairanica.40891

Ce document a été généré automatiquement le 26 septembre 2020.

Tous droits réservés 


\section{Bas Ter Haar Romeny (ed.). Religious Origins of Nations? The Christian Communities of the Middle East}

Florence Jullien

\section{RÉFÉRENCE}

Bas Ter Haar Romeny (ed.). Religious Origins of Nations? The Christian Communities of the Middle East. Leiden, Brill, 2009, XVII-366 p. (Church History and Religious Culture, 89/1-3)

1 Ce numéro spécial est essentiellement consacré à la définition de l'ethnicité syriaque, résultat d'un projet transdisciplinaire de l'université de Leiden. Les conclusions montrent que les facteurs linguistiques et culturels prévalent sur celui de religion en ce qui concerne le sens de l'appartenance communautaire, et que les représentations identitaires doivent beaucoup aux rapports des communautés chrétiennes avec les religions dominantes, tout spécialement l'islam, ce dont l'historiographie se fait particulièrement l'écho. 


\section{AUTEURS}

\section{FLORENCE JULLIEN}

EPHE, Paris 